\title{
CONFLITOS SOCIAIS RELACIONADOS AO TOUR DE SALAR DE UYUNI: relações de poder entre turistas e anfitriões
}

Social conflicts around the Salar de Uyuni tour: power relations between tourists and hosts

Mariana Freitas Gomes de Oliveira ${ }^{1}$

\section{Resumo:}

Cerca de 300.000 turistas visitam o Salar de Uyuni todos os anos, a maioria, estrangeiros. A maior depressão incrustada de sal do mundo é também a atração turística mais importante da Bolívia e o tour dedicado à sua exploração é a principal fonte de renda dos habitantes da cidade. O grande número de visitantes que passam pela área, que é pouco povoada, não poderia deixar o lugar e as pessoas intactas, gerando também a dependência do dinheiro do turismo. Este artigo tem como objetivo analisar os conflitos sociais e culturais decorrentes dessas interações sociais, especialmente as relações de poder entre turistas e anfitriões. Como consumidores, os turistas tendem a exigir ajustes de mercado às suas expectativas, mesmo que se considerem mochileiros. Os anfitriões, por outro lado, apresentam um comportamento considerado por muitos como hostil aos forasteiros. Usando a teoria do conflito de Simmel e a teoria de conflitos culturais de Robinson, este estudo usa os dados coletados no trabalho de campo a partir de entrevistas, observações e participação, para analisar os conflitos entre turistas e anfitriões. Os resultados mostram um sentimento de desconfiança dos anfitriões em relação aos turistas e vice-versa.

Palavras-chave: Salar de Uyuni; mochileiros; sociologia do turismo; relações anfitriãoturista; conflitos sociais.

\begin{abstract}
:
About 300,000 tourists visit Uyuni's salt flats every year, mostly foreigners. The world's largest salt-encrusted depression is also the most important tourist attraction in Bolivia, and the tour dedicated to its exploration is the main source of income for the local population. The amount of visitors passing by the area every day, which is sparsely populated, could not leave place and people untouched, generating dependence on tourism's profits. This article aims to analyze the social and cultural conflicts arising from these interactions, especially the power relations between tourists and hosts. As consumers, tourists tend to demand market adjustments to their expectations of what a visitor needs, even if tourists consider themselves backpackers. Hosts, on the other hand, display behavior deemed by many to be hostile to outsiders. Using Simmel's Conflict Theory and Robinson's Cultural Conflict Theory, this study uses data collected from the fieldwork, interviews, observations, and participation, to analyze conflicts between tourists and hosts. The results show a sense of distrust of the hosts towards tourists and vice versa.
\end{abstract}

\footnotetext{
${ }^{1}$ Doutoranda em Sociologia pela Leibniz Universität Hannover. O artigo é resultado de pesquisa de campo realizada em 2016 na Bolívia e no Chile, com financiamento do Deutscher Akademischer Austausch Dienst (DAAD). Email: marianafreitasgo@gmail.com
} 
Keywords: Salar de Uyuni; backpackers; sociology of tourism; host-tourist relations; social conflicts. 


\section{Introdução}

Chegar a Uyuni de ônibus significa enfrentar as perigosas estradas bolivianas. O que os viajantes encontram é uma cidade empoeirada no meio do deserto, cujo único propósito, ao longo dos anos, se transformou em servir ao turismo. Aninhada em um platô entre duas cordilheiras andinas centrais, a cidade fica às margens do Salar de Thunupa, ou Salar de Uyuni, o mais extenso do mundo com mais de $10.000 \mathrm{~km}^{2}$ (ANDERSEN e VALDEZ, 2010, p. 2). E é exatamente isso o que os turistas querem ver.

Atraindo 300 mil (ACURISMO, 2016) mochileiros a cada ano, o Salar de Uyuni tornouse a paisagem mais famosa da Bolívia por causa das fotos publicadas em mídias sociais mostrando jovens fazendo poses no gigantesco deserto branco. No entanto, a verdadeira magia do Salar acontece durante a estação chuvosa - entre janeiro e março, quando uma fina camada de água repousa sobre o sal no chão, criando um espelho e refletindo as nuvens. $\mathrm{O}$ chamado efeito white out cria a ilusão de que as pessoas estão andando no céu e, portanto, se tornou o Santo Graal do viajante. Com um pouco de sorte e ajuda do guia (que também é motorista e às vezes cozinheiro), os turistas podem fazer a foto perfeita.

O tour padrão ocorre principalmente no Altiplano Andino (o já mencionado platô), levando os mochileiros a lagoas coloridas, gêiseres, vulcões ativos e, claro, o próprio Salar. Tem duração de três dias e duas noites, em uma das quais se passa em hospedagem cujas paredes e camas são feitas inteiramente de sal. Apenas um veículo 4x4 é capaz de conduzir através dos quase $1.000 \mathrm{~km}$ que compreendem toda a viagem, uma vez que em algumas partes do caminho há rochas que podem ser tão grandes quanto os pneus do carro. Há também a areia no deserto que circunda o salar, cactos, corais fossilizados e a altitude de 5.000 metros que o veículo deve aguentar para chegar ao ponto mais alto do passeio. Todos esses elementos compõem o passeio do Salar de Uyuni e tornam-o uma aventura e a possibilidade de experimentar a sensação de estar no meio do nada, em um dos últimos cantos do mundo pouco alterados pela humanidade.

Os viajantes que se interessam por esse tour são em sua maioria jovens dos países vizinhos, como o Brasil, Argentina e Chile, e também da Europa, e possuem características que os definem como mochileiros (HANNAM e ATELJEVIC, 2008, p. 1). Além de hospedar-se em hostels e buscar a economia nas opções de transporte, os mochileiros geralmente seguem viagem rumo a outros pontos de interesse, formando uma rota que se repete e se modifica levemente entre os grupos de amigos e os viajantes solitários. Essa repetição e a rota por ela 
criada forjou a chamada Gringo Trail sul-americana, que inclui também Machu Picchu e o deserto do Atacama. No contexto dessa 'trilha gringa', o Salar de Uyuni se tornou uma das atrações turísticas mais importantes da América do Sul e a "capital turística da Bolívia" (FERNÁNDEZ, 2014), sendo hoje a maior zona de concentrações de recursos governamentais em prol do turismo deste país. Tamanha atenção e o grande número de turistas que passam diariamente por Uyuni e região não poderia deixar de alterar o equilíbrio da paisagem, tanto natural quanto social.

\section{Referencial teórico}

No âmbito desta pesquisa, a categoria de conflitos sociais foi escolhida para representar os desentendimentos, controvérsias e disputas envolvendo os agentes que fazem parte do universo turístico em Salar de Uyuni. Mais especificamente, a teoria do conflito (der Streit) de Georg Simmel $(1964,2015)$ pareceu ser uma ferramenta apropriada para ajudar a entender quais são os conflitos sociais derivados da presença maciça de mochileiros em Uyuni e no deserto circundante. É preciso afirmar, todavia, que o conceito de conflito social, compreendido por meio da teoria de Simmel, não representa apenas confrontos físicos ou políticos, mas também quaisquer oposições ou lutas diárias que qualquer pessoa em qualquer sociedade pode ter com alguém, bem como grupos podem ter um com o outro. Pensando na interação como a matéria prima que compõe o tecido social, Simmel (1964b, p. 570) afirma que "não existe provavelmente nenhuma unidade social onde as correntes convergentes e divergentes entre os seus membros não estejam inseparavelmente entrelaçadas". Portanto, o conflito:

(...) é um componente, um elemento da rotina, que se expressará sob a forma de um gradiente, indo das relações sociais - ásperas - até, às vezes, ao confronto físico. Desta maneira, produzirá uma multiplicidades de arranjos coletivos e sociais derivados desta substância social (JÚNIOR, 2009, p. 9).

É um conceito bastante amplo que foi criticado (JÚNIOR, 2005) por sua suposta falta de objetividade. Em defesa da teoria do conflito de Simmel, deve-se dizer que essa amplitude é útil para pesquisa, pois o cenário estudado é complexo, envolvendo diferentes atores sociais, grupos de interesse e etnias indígenas. Apesar de ser uma investigação sociológica, esta deve ser compreendida de forma interdisciplinar, considerando a cultura local, a geografia, a história e a política como fatores importantes para forjar o turismo em Uyuni. Todas essas camadas sociais são quase invisíveis, a menos que se opte por ver a sinergia entre elas. A amplitude do conceito de conflito em Simmel deve ser considerada, neste caso, não apenas como uma 
ferramenta para organizar, categorizar e enumerar conflitos, mas, mais importante, para sinalizar que os conflitos são o processo em que as mudanças acontecem. O cerne da Vergesellschaftung - sociação na tradução brasileira - é a interação por meio de convergências e divergências, que fazem parte da construção e transformação naturais do tecido social.

No Brasil, o uso da sociologia de Simmel em análises contemporâneas tem se tornado cada vez mais raro. Waizbort (2007, p. 13) oferece três motivos para tanto: 1) não há sociólogos brasileiros que estudaram com Simmel; 2) não há no Brasil uma instituição como a americana Escola de Chicago, que serviria de base para a irradiação de seus conceitos; e 3) há poucos textos de Simmel traduzidos do alemão para o português. De acordo com pesquisa na revista Sociologia, pioneira no Brasil em relação ao tema, a época áurea da recepção dos ensinamentos de Simmel na sociologia brasileira aconteceu entre 1939 e 1955 (LUNA, 1998, p. 20 apud WAIZBORT, 2007, p. 21), onde o autor foi o sociólogo de língua alemã mais citado nos artigos publicados. Naquela época, Simmel era apresentado como um dos mais importantes fundadores da disciplina, sendo citado principalmente para defini-la, para conceber a sociologia formal e para apresentar a discussão dos grupos sociais (idem, p. 21-22 apud WAIZBORT, 2007, p. 22).

A partir de 1955, parece haver um decréscimo da leitura de Simmel, "particularmente no tocante à temática da sociologia geral, continuando a responder perguntas mais restritas como as do conflito e a da situação de estrangeiro" (idem, p. 24-25 apud WAIZBORT, 2007, p. 23). O uso da sociologia do conflito de Simmel na análise dos fenômenos turísticos comprova essa tendência não só no Brasil, mas no mundo. Exemplo é o trabalho de Yang, Ryan e Zhang (2013), onde Simmel aparece como protagonista, juntamente com seu sucessor Coser (1956), no uso do conceito de conflito para explicar a interação entre turistas e anfitriões no Noroeste da China.

Este é o mesmo caminho que este trabalho segue, sendo que no caso a literatura de Simmel soma-se a um trabalho específico à sociologia do turismo. Robinson e Boniface (2005) trazem o conceito de conflitos culturais em quatro dimensões diferentes: turistas-anfitriões, indústria turística-anfitriões, indústria-turistas e anfitriões-anfitriões. Tais dimensões foram aplicadas nesta pesquisa no momento de categorizar os conflitos encontrados durante a pesquisa de campo. No caso, um elemento foi adicionado, que são as instituições governamentais que fazem a regulamentação da atividade turística. Dentre estas várias dimensões em que os conflitos sociais podem ocorrer, este artigo trata especificamente do que Robinson chama de "encontros cara-a-cara", os anfitriões e sua relação com os turistas. 


\section{Metodologia de pesquisa}

Para compreender o encontro entre os dois grupos sociais foi realizada pesquisa de campo em Uyuni e nas cidades adjacentes, especialmente por onde passam o tour e/ou os turistas. Realizada entre Janeiro e Março de 2016, a investigação foi fundamentada na observação participante, metodologia qualitativa "utilizada em estudos ditos exploratórios, descritivos, etnográficos ou, ainda, estudos que visam a generalização de teorias interpretativas" (MÓNICO et al, 2017, p. 725).

A própria natureza adaptativa do método, somada à ideia simmeliana de que o insight é grande parte da análise sociológica, me permitiram experimentar os encontros cara-a-cara de forma imersiva, registrando comportamentos e tendo acesso a informações em primeira-mão. Indo além, durante a observação participante é possível perceber nuances de sentido não só no que é dito, mas também na idiossincrasia diária, "percepcionando emoções e comportamentos de indivíduos com uma determinada identidade grupal, de uma forma que não seria possível obter a partir de um mero questionário" (MÓNICO, 2010, 2011 apud MÓNICO et al, 2017, p. 727). O diário de campo e as fotografias que resultaram desta imersão serviram de importante base para o desenvolvimento desta pesquisa.

No entanto, a natureza do campo - um lugar de fluxo de pessoas, e não uma comunidade mais perene - me impedia de sustentar a investigação apenas com observação participante, sendo necessário complementar a coleta de dados com entrevistas. Tais interações mais focalizadas são descritas por Mónico (2017, p. 727), como "uma oportunidade para o investigador verificar o seu entendimento das coisas, em comparação com a interpretação daqueles que estiveram a ser observados, e para obter informação adicional e relevante para o estudo". Estas foram realizadas a partir de quatro questionários semi-estruturados, cujos tópicos abordados variavam de acordo com o grupo social do qual o entrevistado fazia parte.

A escolha dos sujeitos da pesquisa, especialmente entre os turistas, se deu na imprevisibilidade do campo e dia-a-dia em hotéis e hostels, sendo feita por conveniência. Já os representantes de entidades governamentais, de classe e da indústria foram contatados primeiro por telefone a partir de indicações e intermediações de quem ia sendo encontrado no caminho. Dificuldade maior foi criar aproximação com os habitantes do local que não estavam envolvidos diretamente com o turismo. Os grupos sociais anteriores eram mais abertos ao fato de eu parecer tão forasteira quanto qualquer turista e, em segundo plano revelar-me pesquisadora, enquanto os locais fechavam-se contra qualquer aproximação minha. A solução encontrada para esta 
dificuldade foi aprofundar-me nas entrevistas atores de outros grupos sociais, na literatura específica e na observação.

Um questionário semi-estruturado me permitiu adaptar meus questionamentos à posição social dos atores envolvidos e enveredar-me pela complicada trama histórico, político e econômica que compõe o turismo em Salar de Uyuni. Outras perguntas para além da relação turista-anfitrião estavam incluídas, já que esta pesquisa faz parte de um projeto maior que culmina em minha tese de doutorado, em que os quatro grupos sociais em questão (turistas, anfitriões, governo e indústria) interrelacionam-se organicamente. $\mathrm{O}$ que interessa para este artigo, no entanto, são estas duas faces do turismo de aventura em Salar de Uyuni e como se dá a interação social que gera inevitáveis conflitos sociais.

Os resultados destes questionamentos em específico serão apresentados durante o artigo da seguinte forma: na primeira seção são descritos mochileiros e indígenas, bem como conceitos e espaço social ocupado por ambos os grupos. Tal descrição é seguida pela explicação da metodologia de coleta e análise dos dados, amplamente modificados pelas próprias condições do cenário encontrado durante a pesquisa de campo. A segunda seção trata da apresentação dos conflitos sociais identificados entre turistas e anfitriões, suas raízes culturais e as tentativas do governo de minimizá-los. A seguir, são recontadas as experiências dos turistas em relação à hospitalidade dos bolivianos e, na seção seguinte, também o outro lado da moeda, sendo apresentadas as experiências dos anfitriões com os estrangeiros. Por fim, apresento minhas considerações finais e conclusões do trabalho.

\section{O encontro dos mochileiros com os indígenas bolivianos}

O "mochilão" (derivado do inglês backpacking) é uma das modalidades de viagem que vem ganhando adeptos nos últimos anos (HANNAM e ATELJEVIC, 2008, p. 1), caracterizada principalmente pela busca por economia. Esta é alcançada com a hospedagem em albergues/hostels, bem como com a procura de passeios turísticos mais baratos do que os coordenados por agências - quando isso é possível -, e também pelos longos períodos de viagem e a mochila nas costas (idem, p. 1). Outra característica interessante deste tipo de viajante é a ânsia por conhecer várias cidades e países em uma única viagem. Apesar da busca pelo mínimo de gasto, os mochileiros movimentam a economia de cidades inteiras e são hoje um público-alvo de inúmeros produtos. Para além do fator financeiro, os mochileiros formam 
uma comunidade imaginada (APPADURAI, 1996), um grupo não institucionalizado, mas relativamente coeso em suas dinâmicas próprias.

Existem atributos comuns aos que integram esta comunidade, ritos de adesão ao grupo e formas particulares de lidar com o turismo. O rótulo "turista" pode inclusive ser um problema para alguns mochileiros (HANNAM e ATELJEVIC, 2008), que pretendem fugir das rotas tradicionais por considerarem-nas "artificiais", advogando em prol de passeios em comunidade sem o intermédio de agências especializadas. Outro atributo desse grupo é a relativa flexibilidade do roteiro, o que permite a permanência por períodos de tempo maiores em determinadas cidades, provocando às vezes a busca por empregos temporários ou prestação de serviços em troca de estadia e alimentação (ALLON, ANDERSON e BUSHELL, 2008). Tudo isso torna os mochileiros um gênero de viajante próprio e distinto dos adeptos ao turismo "de massa", termo que aparece em Krippendorf (1989), por exemplo, como atividade "passiva". Essa modalidade, que cresce vertiginosamente ao longo dos anos, vem provocando impactos econômicos significativos em regiões como a Ásia (UNESCO Bangkok, 2004) e América Latina.

Na América do Sul, como já dito acima, uma das regiões que mais recebe mochileiros é o Altiplano Andino, que compreende desde o lago Titikaka até o deserto do Atacama. O Salar de Uyuni representa um ponto de confluência dos mochileiros vindos do norte, a partir de La Paz, e do sul, a partir do Chile e da Argentina. A passagem por Uyuni significa também o encontro com "o homem andino", como me foi descrito durante a pesquisa de campo, que é caracterizado por ter a personalidade "fechada". Os aimara, segundo a tese mais aceita, derivam da cultura Tiwanaku, cujos resquícios da capital ainda podem ser encontrados em um sítio arqueológico próximo a La Paz. Esta antiga civilização fez frente aos Incas e dominou o Altiplano Andino, que também é chamado em espanhol de meseta del Collao, significando "lugar dos collas", nome dado até hoje aos bolivianos pertencentes a esta etnia. Os collas caracterizam-se por falar o idioma aimará e, as mulheres em especial, por usarem trajes típicos da era colonial, como saias rodadas e chapéus cocos que as distinguem do restante da população. A presença dos aimara se concentra no Altiplano Andino, um pouco do norte do Chile e sul do Peru. 


\section{Conflitos sociais e culturais}

Ao contrário de outros destinos turísticos, no tour de Salar de Uyuni não há apresentação da cultura local por meio de danças ou representações teatrais de qualquer tipo. O foco é a paisagem e a natureza, e o único encontro com moradores locais se dá na cidade de Colchani, um povoado a $20 \mathrm{~km}$ de Uyuni nascido dos trabalhadores da extração do sal, mas que hoje vive também das tendas e lojas de vendas de souvenires, muito dos quais são produzidos no Peru. Os turistas passam por Colchani no começo ou no fim do tour, a depender de onde o começaram, e ali tem contato com os bolivianos que estão a vender os artigos destinados aos viajantes. A única outra possibilidade de o encontro entre anfitriões e mochileiros acontecer é em uma das paradas para almoço feitas durante o tour, geralmente em vilarejos minúsculos no meio do deserto, habitados por trabalhadores das empresas que extraem minérios da região.

Devido a esta característica, os "encontros cara-a-cara" acontecem em Uyuni, onde os turistas se hospedam antes e depois de realizarem o tour. A cidade é apenas um ponto de entrada ou saída do tour de quatro dias, e não oferece muitas atrações que façam com que os estrangeiros fiquem mais tempo no local. Apesar disso, a impressão que Uyuni deixa nos turistas é marcante. Em minha pesquisa de campo, não encontrei um único estrangeiro que tivesse boas memórias da cidade, a descrevendo como hostil.

Uma jovem norueguesa, inclusive, me disse que "não via a hora de sair de lá" e que “detestou” tudo. Tais palavras podem parecer fortes, mas são compreensíveis por quem já foi a Uyuni e não se sentiu acolhido pelos locais. Uma lembrança que tenho de minha chegada à cidade, na ocasião para começar a pesquisa de campo, envolve o dono de um hotel na rua da rodoviária que, ao me receber, disse ao jovem recepcionista que ele poderia cobrar mais caro de mim por ser gringa. Sem trocar uma palavra comigo, ele não poderia saber que sou fluente em castelhano e que entendi tudo o que dizia.

A explicação da responsável pela secretaria de turismo da cidade de Uyuni para o tratamento dos anfitriões com os turistas seria a falta de campanhas de educação e conscientização dos moradores e trabalhadores da indústria turística da importância de receber bem os estrangeiros:

Recién hemos realizado aqui a la unidad de turismo lo que se trata de hacer la sensibilización turística con la población de Uyuni. Yo ingresé en Septiembre y eso es lo que estamos aprovechando en mes internacional de turismo para hacer, actividades conjuntamente con las asociaciones gastronómicas y también con operadores de turismo que también ahí hay asociaciones. Pero así, la gente todavia no está muy... pasa que viven del turismo pero no tienen todavia un buen trato hacia el turista. Pero, como te comento, nunca se ha tratado eso. Hay muchas cosas que en el turismo que todavia no se ha hecho aqui. Está, por ejemplo, en painel. No se ha tratado 
nada, lo único que he visto que han realizado durante los anos es hacer así el material. Todo lo que es material, a mi forma de ver es material institucional, pero solo giran en torno aqui y la gente de aqui no se recibe el material. No se ha elaborado un material que sea por internet, o tal vez en otros idiomas (grifo meu, entrevista concedida a autora, 2016) $)^{2}$

Outro fator nomeado pela secretária de turismo seria a falta de opções de lazer e atrações ofertadas aos turistas, que se tornam reféns das agências na compra de pacotes para o tour padrão pelo salar e arredores. Por não haverem opções, a passagem do turista por Uyuni é curta ${ }^{3}$, e a solução para o problema seria fazer com que os habitantes das cidades da região promovessem atrativos turísticos.

También lamentablemente, lo único que trabajan es el Salar de Uyuni. Tampoco se ha realizado, se ha extendido la oferta. El turista también viene aquí y no hay otra cosa más que hacer que el Salar. También se está tratando de hacer unas jornadas para poder ir a los diferentes pueblos que tienen atractivos turísticos porque más que nada tal vez durante este medio año hacer que la gente se vea que el turismo es una actividad económica pero también es una actividad donde pueden donde se puede sacar muchos beneficios en relaciones humanas que se pueden intercambiar (entrevista concedida a autora, 2016) ${ }^{4}$

O turismo como atividade econômica perde, neste caso, a preferência dos habitantes do Altiplano por ser um "trabalho de ano inteiro", ao contrário do cultivo de quinoa, por exemplo, que só acontece em temporadas específicas devido à estação chuvosa. Percebe-se, portanto, que não há intenção por parte dos moradores das cidades e povoados vizinhos de investir no turismo. A consequência desse comportamento é o número de pessoas originárias de La Paz que vivem hoje em Uyuni e são donos da maioria dos restaurantes, agências e hotéis na praça principal da cidade, a Plaza Arce.

\footnotetext{
${ }^{2}$ Acabamos de fazer aqui para a unidade de turismo a conscientização do turismo com a população de Uyuni. Comecei em Setembro e aproveitamos o mês internacional do turismo para fazermos atividades em conjunto com as associações gastronômicas e também com os operadores turísticos e suas associações. Mas desta forma, as pessoas ainda não são muito ... acontece que eles vivem do turismo, mas eles não têm um bom tratamento para os turistas ainda. Mas, como eu te disse, isso nunca foi discutido. Há muitas coisas no turismo que ainda não foram feitas aqui. É, por exemplo, no painel. Nada foi tratado, a única coisa que vi que fizeram ao longo dos anos é fazer o material. Tudo o que é material, ao meu modo de ver, é material institucional, mas eles só circulam por aqui e as pessoas daqui não recebem o material. Nenhum material foi desenvolvido online ou talvez em outros idiomas.

${ }^{3}$ Em termos de hospedagem e alimentação, Uyuni é mais cara que as grandes cidades bolivianas com fortes atrativos turísticos, como La Paz e Potosí. O fato de a cidade ser isolada e não produzir alimentos deve também ser considerado, porém, a disparidade de preços afasta os mochileiros que preferem ficar mais tempo em cidades mais baratas e que tenham maior oferta de atrativos.

${ }^{4}$ Também, infelizmente, a única coisa que funciona é o Salar de Uyuni. A oferta não foi aumentada. O turista também vem aqui e não há mais nada a fazer além do Salar. Estamos tentando fazer jornadas para ir para as diferentes povoados que têm atrações turísticas, porque mais do que qualquer coisa talvez durante estes seis meses fazer as pessoas verem que o turismo é uma atividade econômica, mas também é uma atividade de onde eles podem obter muitos benefícios em relacionamentos humanos que podem ser trocados
} 
Esse traço da população local e sua influência no turismo não são novos e já foi mencionado anteriormente em um estudo sobre o turismo comunitário na Bolívia. Aranibar, professor de turismo em uma universidade em La Paz e ex-Ministro do Turismo boliviano, analisou em sua tese de doutorado o turismo indígena e comunitário em todo o país. Segundo ele,

Cada sociedade indígena organiza sua vida cotidiana dando prioridade à satisfação de necessidades materiais e espirituais básicas. "Cada dia um grupo decide a ocupação do tempo de cada membro da comunidade, seja pescando com anzol ou rede, coletando frutas, caçando, preparando a fazenda, fazendo uma coroa cerimonial, etc. Uma das características da vida indígena é a enorme liberdade que uma pessoa tem, dentro dos limites estabelecidos pelas estratégias de sobrevivência, para decidir como ocupar seu tempo. Em geral, as horas utilizadas para atividades materiais de subsistência são em média de 3 a 4 horas por dia. Cada pessoa adulta é a sua própria autoridade e decide como deve fazer para satisfazer as necessidades diárias do seu agregado familiar. Os ritmos produtivos respondem a razões sazonais e aos ciclos de maturação de frutos ou culturas silvestres, migrações de animais ou peixes, etc. $\mathrm{O}$ artesanato em tecelagem ou cerâmica é praticado especialmente na estação chuvosa, assim como a troca de mercadorias e presentes é feita na estação seca, quando as trilhas e os rios são transitáveis. Tendo em conta estes fatores de racionalidade indígena pode tornar a viabilidade e sustentabilidade das empresas de turismo indígenas e comunitárias. (2009, p. 90-91, tradução minha)

Para Aranibar (2009, p. 91), para resolver esse problema seria necessário respeitar a cultura indígena no que diz respeito às suas concepções de tempo e trabalho, utilizando a sua "racionalidade organizativa" para combinar o "individual e coletivo em um modelo misto que vem funcionando adequadamente há séculos e que pode muito bem se adaptar ao desenvolvimento do turismo comunitário" (idem, ibidem, p. 89, tradução minha). A tese de Aranibar afirma que é preciso adaptar o turismo ao modo de vida indígena e não o contrário, integrando as comunidades a essa indústria para que elas possam também usufruir de seus rendimentos sem que tenham que alterar suas características ancestrais.

Seu trabalho acadêmico e sua posição no setor governamental responsável por planejar, promover e regular o turismo influenciaram muito na forma com que o governo de Evo Morales encara a atividade turística. Após seu mandato, a Bolívia lançou seu primeiro Plan Nacional de Turismo 2012-2016, que trouxe um documento completo com metas e ações para aprimorar esta atividade econômica que vinha crescendo exponencialmente ao longo dos anos. Além de metas financeiras importantes, como "posicionar o Setor de Turismo como a primeira atividade geradora de moeda estrangeira no setor exportador não tradicional” (PLAN, 2012, p. 42, tradução minha), o Plano traz uma meta específica relacionada à hospitalidade: "bolivianas e bolivianos conscientes do turismo e orgulhosos de seu patrimônio cultural e natural" (Idem, ibidem, p. 42, tradução minha). 
A ideia de tornar o povo orgulhoso de seu patrimônio e sensibilizá-lo quanto à atividade turística parece condizer com o retrato de uma nação que busca ser referência sul-americana em termos de turismo. Os instrumentos usados para alcançar essa meta seriam, de acordo com o Plano, seminários e workshops, além de material impresso distribuído à população. Apesar de bem intencionado, é possível ver por meio da primeira entrevista citada por mim, que as políticas não foram efetivadas e o material institucional acabou sendo estocado pelos órgãos locais de turismo, não chegando ao público-alvo. Em consequência disso, não é possível medir a efetividade dessa política.

\section{Hospitalidade e autenticidade: como se recebe o turista em Uyuni}

Um episódio que me marcou bastante durante a pesquisa de campo foi minha passagem por Colchani, o já mencionado vilarejo onde se vende artesanato e souvenires aos turistas que fazem o tour de Salar de Uyuni. Caminhando pelas ruas, me lembrei do primeiro tour que fiz em 2012, quando "mochilei” pela Bolívia. Naquela época, Colchani era composta por duas fileiras de casas e uma rua comprida, onde todo o comércio acontecia. Em 2016, somente quatro anos depois, ao realizar a pesquisa de campo percebi que Colchani havia quintuplicado de tamanho, sem contar com as inúmeras casas em construção naquele momento. Tudo resultado do crescimento do número de turistas no Altiplano Andino.

No entanto, não é o crescimento acelerado do vilarejo que marcou, mas sim a hostilidade dos trabalhadores da indústria do sal, que continuam usando Colchani como base para a extração do mineral. Ao visualizar de longe um caminhão com sal ser descarregado por quatro homens usando pás como instrumento para isso. Achei a cena interessante e fui tirar uma foto. Não só eu, mas um grupo de turistas - presumo europeus pelas características - teve a mesma ideia. Chegando próximo ao caminhão, os homens ficaram incomodados com as fotos e tornaram-se um pouco agressivos, jogando pedras de sal em mim e no grupo de turistas. A mensagem era clara: saiam daqui e nos deixem em paz.

Não fiquei especialmente ofendida pela reação dos trabalhadores, até porque não foram os primeiros a gritar comigo e com a minha câmera fotográfica durante minha estadia na Bolívia. O que me chamou a atenção foi o incômodo causado pelos turistas aos habitantes de uma região, em especial para os que não estão diretamente envolvidos com o turismo, assunto amplamente debatido em estudos anteriores (JAMAL e ROBINSON, 2009). Tendo em mente 
a interação descrita, eu não tentei entrevistar estes homens, mas me foi explicado o porquê de os habitantes de Colchani que trabalham com o sal verem os turistas como um empecilho.

A técnica usada para extrair o sal do salar é simples e manual até hoje, consistindo apenas três etapas: formar montes de sal com uma pá, esperar o sol evaporar a água e carregar o sal em um caminhão. Tanto que, em minha primeira visita a Colchani em 2012, pude ver os tais montones de sal próximos à cidade. Hoje em dia não é mais possível ver a extração do sal tão de perto, pois os trabalhadores, cansados de ver os turistas subindo nos montes de sal para fazer fotos e destruindo seu trabalho, começaram a realizar esse serviço em outra parte do salar. Isso explica o incômodo causado pelos turistas que, assumindo que todos ao seu redor estão a serviço de seu entretenimento, não pensam nas reais consequências de suas ações.

O episódio em Colchani traz a oportunidade de discutirmos não só a hospitalidade dos bolivianos com os turistas que visitam o Salar de Uyuni, mas também até que ponto podemos esperar que essa hospitalidade não seja encenada, mas sim autêntica. O tema da autenticidade nas pesquisas de turismo é antigo e já discutido (SANTANA, 2009; BARRETO, 2007), mas não deixa de ser relevante no processo em questão. Inclusive, os próprios turistas possuem suas inquietações a respeito disso. Um brasileiro, quando questionado a respeito de suas interações com os bolivianos, me disse:

(...) uma pessoa ou outra que acabei tendo uma relação mais próxima, mas acho que não é um traço do lugar ter esse tipo de comportamento. Eu acho muito difícil separar as coisas também. Até que ponto quando você começa a interagir com o local aquilo tem a ver com uma proximidade concreta ou só tem a ver com o fato daquela pessoa ter a consciência de que você é um turista e que se ela for agradável com você aquilo pode gerar uma impressão de aquele lugar é simpático ao turismo e você vai voltar para o seu lugar e falar "lá o pessoal é maneiro pra caralho". Então, sei lá, para mim é meio difícil ter essa clareza de interação com as pessoas (entrevista concedida a autora, 2016).

É possível perceber que os turistas entrevistados durante a pesquisa desejam ter, afinal, relações verdadeiras e autênticas com os lugares e pessoas que visitam, ao invés de tornaremse expectadores de teatros montados para entretê-los. Naturalmente, nenhum turista deseja ser maltratado por seu anfitrião, onde quer que esteja, mas quando se visita um lugar como Uyuni, em que as pessoas e suas culturas não fazem parte do pacote, a hospitalidade cai para segundo plano.

A aventura e as paisagens naturais são o tema do turismo ali e o que eu encontrei, na verdade, são turistas com grande preocupação com o meio ambiente. Por se tratar de áreas protegidas e muito delicadas quando se trata de equilíbrio entre ser humano e natureza, o Altiplano Andino escancara aos visitantes o impacto ambiental da atividade turística. Como 
dito antes, o tour é sempre feito em um carro $4 \times 4$, devido às condições do terreno, e como o volume de turistas é muito grande, é possível ver dezenas destes carros atravessando o salar e os desertos adjacentes, deixando suas marcas.

Durante o tour também são feitas várias paradas para fotos, sejam em lagoas, vulcões ou formações rochosas extraordinárias. O problema aqui é a falta de infra-estrutura para receber esses turistas, já que não há banheiros ou plataformas/caminhos por onde eles devam passar e onde devem se ater. Uma turista canadense resume:

I'd say one thing there that stood out was the lack of infrastructure on those places where every tour goes to and it's in these fragile environments, but there is no facility for people to use the toilet and, you know, you could always find behind the big rock a bunch of toilet paper and it stinks. For a place where so many people are visiting someone would invest on something to take care of that, but I guess it is a question of who (entrevista concedida a autora, 2016) $)^{5}$

Sua última frase resume a questão de quem seria o responsável por garantir essa estrutura e a resposta mais coerente seria o governo, seja em nível nacional ou departamental. Mas nem sempre é o que acontece e algumas comunidades às vezes resolvem realizar elas mesmas as melhorias necessárias. Algumas medidas interessantes que foram implementadas ao longo dos anos são a manutenção das termas e o fechamento do hotel de sal. As termas são piscinas naturais de água quente localizadas dentro da Reserva Nacional de Fauna Andina Eduardo Avaroa (REA) e já há muito tempo fazem parte do tour padrão. Nas proximidades das termas foram construídas estruturas para receber os turistas, com banheiros, áreas para refeições e locais de descanso. Os responsáveis não fazem parte do estado, mas sim são os moradores de Sur Lípez, uma província no extremo sul do país, da qual falarei mais a seguir.

Já o fechamento do hotel de sal partiu do governo boliviano. Este hotel em questão está localizado no meio do salar e desde 2010 já não recebe mais hóspedes. Seu fechamento se deu por conta da preocupação com a contaminação do salar com detritos dos banheiros do hotel, segundo relato do meu guia em 2012. É interessante notar que, apesar de fechado para hóspedes, o hotel continua aberto para visitação e possui banheiros funcionando. Ele ainda faz parte do tour padrão e faz parte de uma das imagens mais conhecidas, que é a plataforma com bandeiras de diversos países deixadas por turistas em suas passagens por lá.

\footnotetext{
${ }^{5}$ Eu diria que uma das coisas que se destacou foi a falta de infraestrutura nestes lugares onde todos os tours vão e nestes meio ambientes frágeis, onde não há lugar para as pessoas irem ao banheiro e, você sabe, você sempre encontra um monte de papel higiênico atrás de uma rocha grande e fede. Para um lugar que recebe tanta gente alguém deveria investir em alguma coisa e cuidar disso, mas eu acho que seja uma questão de quem.
} 
O cuidado com o meio ambiente me parece uma preocupação válida dos turistas da área e cria conflitos entre estes e seus anfitriões, mas não o faz de forma direta, pois não são os anfitriões os responsáveis por promover as mudanças necessárias nesse quesito. E os turistas, por outro lado, não podem exigir tamanha regulamentação devido ao caráter temporal de sua estadia. O que afeta os turistas de verdade e é causa de diversos conflitos é a infraestrutura dos hotéis em que se hospedam. O hotel de sal mencionado anteriormente foi apenas o primeiro dos muitos que existem hoje ao redor do salar. Estes seguem em funcionamento e fazem parte do tour, mas, por estarem localizados em áreas com difícil acesso à água, banheiros e duchas podem simplesmente não estar disponíveis, o que causa conflitos.

Outro problema enfrentado pelo turista é a falta de preços tabelados e de um maior rigor na regulamentação dos serviços ofertados pelas agências que fazem o tour. A barganha faz parte da cultura boliviana e está presente em praticamente todas as transações comerciais, e o turismo não está fora desta. Por isso, o turista precisa geralmente pesquisar preços, indo de agência em agência e pedindo desconto. Como todas oferecem o mesmo pacote, passando pelos mesmos lugares, é normal o turista acabar por fechar negócio com a agência que cobra menos. No entanto, isso traz dois problemas. O primeiro é encontrar pelo caminho alguém viajando com outra agência que oferece o mesmo pacote por muito menos. Em casos extremos em que o turista decide reclamar com a Policía Turística, a secretaria departamental de turismo entra em cena. Em entrevista concedida a autora (2016), o representante do governo departamental de Potosí para o turismo em Uyuni exemplifica:

El paquete se vende a 700 bolivianos, compra a todo el paquete y esta listo e encuentran una operadora que lo vende a 500 bolivianos. Hasta la semana pasada hemos tenido un problema igualito a esto. Habían comprado un paquete de dos días de 500 bolivianos. Se fueran a dar una vuelta y encontraran el mismo paquete por 200 bolivianos. Las operadoras se encontraran en el Salar. Los dos amigos eran de Uruguay, emperrados a conversar y trocar experiencias y vieron que era el mismo tour, el mismo servicio, pero una operadora cobraba más y otra menos. Entonces hubo un problema aquí y tuvimos que hacer devolver un tanto el dinero de la otra operadora porque no era un servicio más. Y yo creo que es de esta manera. Hay turistas que son muy educados, pero hay muchos turistas que son mal entretenidos que se portan mal. De los chicos que te dije, los dos ellos igual, fueron en la otra operadora y empezaron a chutar su puerta, y me enoje y fui con la policía y les hice subir a su bus y irse. ${ }^{6}$

\footnotetext{
${ }^{6} \mathrm{O}$ pacote é vendido por 700 bolivianos, um turista compra todo o pacote e está pronto e encontra um operador que o vende por 500 bolivianos. A semana passada nós tivemos um problema como esse. Eles haviam comprado um pacote de dois dias de 500 bolivianos. Eles deram uma volta e encontraram o mesmo pacote para 200 bolivianos. Os tours já estavam no Salar. Os dois amigos eram do Uruguai, ansiosos para conversar e trocar experiências e viram que era o mesmo tour, o mesmo serviço, mas um operador cobrava mais e menos outro. Então houve um problema aqui e nós tivemos que fazer um reembolso do dinheiro do outro operador porque não era um serviço a mais. E eu acho que é assim. Há turistas que são muito educados, mas há muitos turistas mal educados que se comportam mal. Dos caras que eu lhe contei, os dois eram os mesmos, eles foram até a outra operadora e começaram a chutar a porta, e eu fiquei com raiva e fui até a polícia e fiz com que eles pegassem o ônibus e partissem.
} 
Nesse caso, dois turistas uruguaios levaram ao extremo sua insatisfação com a diferença de preços e partiram para a violência, sendo convidados a se retirar da cidade. $\mathrm{O}$ caso é raro e normalmente o máximo que os turistas fazem é reclamar da agência em fóruns na internet, onde muitos pedem recomendações. Outra consequência da dinâmica das agências em Uyuni é a imprevisibilidade. Quando se fecha o pacote com uma agência e esta não consegue completar um grupo de seis pessoas para viajar, as agências tendem a se juntar para fechar um ou mais carros e evitar mandar um tour com menor capacidade do que o possível. Nesse caso, um turista brasileiro reclama:

E outro lance que eu também acho que não foi muito legal que é esse lance de você contratar em uma agência e ter esse serviço terceirizado em que você nunca sabe muito bem o que você está contratando, sabe? Por exemplo, aconteceu comigo. Bota a lista aqui e esse é o teu grupo, você vai lá e bota o seu nome. Aí você vê e tem um brasileiro e um francês. No outro dia já eram outras pessoas que estavam [na lista] (entrevista concedida a autora, 2016).

Apesar de todos os conflitos entre turistas e anfitriões listados acima, existe um que afeta muitos turistas: a própria dinâmica do tour. O tour de Salar de Uyuni me foi descrito por um entrevistado como "tour de japonês", pois se viaja de carro por muitos quilômetros com diversas rápidas paradas no caminho para tirar fotos. Isso causa dois incômodos aos turistas. Um deles é a falta de tempo para apreciar o local e o outro é encontrar em cada parada dezenas de carros também lotados de turistas, destruindo a sensação de estar só em um local isolado. O guia da minha viagem descreve esse ponto da seguinte forma:

lo que ha experimentado es que los turistas siempre quieren caminar solos en el desierto. La mayoría dice "queremos andar solitos, no queremos mucha gente". Antes si era mucha la posibilidad de caminar solo pero ahora no tanto. Tentamos caminar solos pero siempre aparecen um coche por tras, otro coche adelante (entrevista concedida a autora, 2016$)^{7}$

Muitos outros relatos me confirmaram o mesmo, o que mostra que, ao fim do dia, o que realmente incomoda os turistas são os outros turistas.

\section{Convivendo com os mochileiros}

Como descrito acima na passagem sobre Colchani, os turistas causam incômodo principalmente aos moradores de Uyuni e região que não estão diretamente envolvidos com o

\footnotetext{
${ }^{7}$ Minha experiência mostra que os turistas sempre querem andar sozinhos no deserto. A maioria diz "queremos andar sozinhos, não queremos muitas pessoas". Antes sim havia muita possibilidade de andar sozinho, mas agora não tanto. Nós tentamos estar mais isolados, mas sempre aparece um carro por trás, outro carro pela frente.
} 
turismo. Em minha entrevista com o guia de meu tour sobre essa relação turista-boliviano, recebi como resposta:

A principios, cuando nosotros habíamos hecho ingresar a los turistas, [los bolivianos ]tenían un concepto muy malo acerca de los turistas. Especialmente los que en Bolivia han aplastado mucho, digamos la capitalización, vean a un, disculpe la palabra, quizás no es la palabra más correcta para identificar a las personas, siempre los identificamos como gringos. Y muchos nativos decían "no dejen a venir los gringos porque ellos van a ver nuestros minerales, vienen a observar nuestras riquezas naturales y un dia van a invertir un capital y ustedes que son los guías de estos gringos, ustedes son como traicioneros, nos están queriendo nos traicionar”. Este concepto tenía la gente de los pueblitos pequeños. No querían que ingresen los gringos, pero con el futuro nosotros hemos ido explicando, los guías, que nos es tanto así. Ellos no tienen mucho interés en los recursos naturales. Solamente vienen ellos a despejar su mente, a pasar un momento de vacación (...). Vienen, en otras palabras, a despejar su estrés como salir a la libertad. Y compreendendo ese concepto ya el turista es aceptable en Bolivia. Pero a principios era complicado aceptar eso, en los pueblitos era complicado (entrevista concedida a autora, 2016) ${ }^{8}$

Os pueblitos em questão não são necessariamente Uyuni, apesar desta não ser uma grande cidade, mas sim os vilarejos de quatro a dez casas localizadas no meio do deserto, espalhados mais ao sul. São residências dos indígenas que cultivam quinoa, criam llamas ou trabalham nas mineradoras que exploram a região. Estes servem apenas de passagem dos turistas em paradas para o almoço e nestas ocasiões, mais parecem cidades fantasmas com casas de terracota e telhados de palha. Por isso, quase não há "encontro cara-a-cara" entre turistas e os moradores destes lugares, tornando essa população quase invisível aos olhos dos viajantes.

Uma exceção é a já mencionada província de Sur Lípez, onde se encontram as vilas de Quetena Grande e Quetena Chico, lugares um pouco maiores localizados na fronteira com a Reserva Eduardo Avaroa. Ali os carros e seus passageiros pernoitam e, para isso, precisam pagar uma taxa na entrada. Essa taxa é diferente da cobrada pelo governo nacional na entrada da Reserva, administrada pelo exército. Em Sur Lípez, o que é cobrado vai para os cofres da comunidade e servem para administrar os locais por onde passam os turistas. Uma das melhorias trazidas por esse capital foi a construção na região das termas, como eu disse anteriormente.

\footnotetext{
${ }^{8}$ No início, quando fizemos os turistas entrarem, os bolivianos tinham um conceito muito ruim sobre os turistas. Especialmente aqueles que na Bolívia têm sofrido muito, dizem em voz alta, veja, desculpe a palavra, talvez não seja a palavra mais correta para identificar pessoas, nós sempre as identificamos como gringos. E muitos nativos disseram: "não deixem os gringos virem porque vão ver nossos minerais, eles vêm observar nossas riquezas naturais e um dia eles vão investir uma capital e vocês que são os guias desses gringos, vocês são tão traiçoeiros, estão querendo nos trair ". Esta ideia tinham as pessoas de pequenas cidades. Eles não queriam que os gringos entrassem, mas com o tempo temos explicado, os guias, que somos muito parecidos com eles. Eles não têm muito interesse em recursos naturais. Só eles vêm limpar suas mentes, passar um momento de férias (...). Eles vêm, em outras palavras, para limpar o estresse quando saem para a liberdade. E entender esse conceito e o turista é aceitável na Bolívia. Mas no começo era complicado aceitar que, nas pequenas cidades, era complicado
} 
O processo de estabelecimento de Sur Lípez como uma província independente na cobrança de taxas aos turistas veio de uma mobilização realizada em 2012, presenciada por mim em minha primeira viagem à Bolívia que muito contribuiu para o nascimento dessa pesquisa. Na época, os moradores da província protestavam contra as agências que centralizavam os lucros do turismo e reivindicavam que estes fossem repartidos pelas comunidades afetadas pela presença dos turistas. O resultado dessa mobilização é a cobrança desta taxa nas principais rotas de entradas dos turistas. Outra benesse trazida por esta cobrança se encontra na região onde está localizada a árvore de pedra, um outro atrativo importante no tour. A ação do vento ao longo dos milhares de anos fez essa rocha assumir a forma de uma árvore, perfeita para as câmeras interessadas dos mochileiros. Também nesse local foi construída uma estrutura com banheiros para atender as centenas de pessoas que passam ali diariamente.

A árvore de pedra também sofreu com conflitos de outra natureza. De acordo com o oficial departamental de turismo em Uyuni, um grupo de israelenses viajou à cidade carregando explosivos com o objetivo de fazer o tour e explodir a rocha. Não encontrei outras fontes sobre o assunto, mas o oficial me relata que a solução foi simples: "los hicimos hablar con policias y los despachamos". Mesmo a polícia turística de Uyuni não me confirmou o fato e, em entrevista não gravada, uma moça me relatou que os conflitos encontrados por ela entre turistas e anfitriões se resumem a relatos de roubo. De acordo com a policial, o que os turistas apresentam são roubos de bagagem ou equipamento fotográfico dentro dos próprios hotéis. Durante a entrevista, contudo, avaliei que sua fala estava carregada de cinismo e, com isso entrega uma opinião. "Eles na verdade querem o seguro e precisam do papel", admitindo incredulidade nos estrangeiros e acrescentando que Uyuni é uma cidade pacata com pouca ou nenhuma violência.

Esse sentimento de desconfiança para com o estrangeiro explica a timidez dos anfitriões e até mesmo a ocasional hostilidade sentida pelos turistas. De novo lanço mão da entrevista com o guia do tour realizado durante a pesquisa de campo:

Hay mucha gente, los nativos de los pueblitos, tienen un concepto - no sé si vale la pena aclarar esto, quizá va parecer como si fuera algo ridículo - donde dicen: "los gringos vienen a reírse de nosotros, vienen a burlarse de nuestra raza, ellos son personar decentes, nosotros somos personar muy diferentes, ellos utilizar perfume, nosotros somos naturales". Se hice fuerte la discriminación y previene la relación intima entre visitantes y entre nativos. Eso lo que he comprendido yo. (entrevista concedida a autora, 2016) ${ }^{9}$

\footnotetext{
${ }^{9}$ Há muitas pessoas, os nativos das pequenas cidades, têm uma ideia - não sei se vale a pena esclarecer isso, talvez pareça algo ridículo - onde dizem: "os gringos vêm rir de nós, vêm tirar sarro da nossa raça, são pessoas decentes e nós somos pessoas muito diferentes, usam perfume, somos naturais". A discriminação tornou-se forte e impede a relação íntima entre visitantes e entre nativos. Isso é o que eu entendi.
} 
Essa descrição corrobora com a ideia que me foi apresentada pela oficial municipal de turismo em Uyuni, a de que o povo andino seria "fechado", impossibilitando uma relação melhor com os estrangeiros. Outros me apresentaram também essa ideia, mas houve também muitos os que defenderam a presença dos turistas para mim. Relacionando o turismo com progresso econômico e carregado de orgulho das paisagens naturais de sua terra, um senhor me disse crer que é preciso "receber bem o turista". Até porque, como me foi dito, "la mayoría de los turistas son tranquilos. Hasta porque se quedan en Uyuni тиу poco”.

\section{Considerações finais}

Os "encontros cara-a-cara" entre os mochileiros estrangeiros e os indígenas no Altiplano Andino geram uma série de conflitos sociais e culturais que permeiam todas as relações e têm consequências práticas, políticas e econômicas para a região. Como Simmel (1999, 2015) descreveu, esses conflitos cotidianos são responsáveis por mudanças estruturais e de comportamento. Olhando o panorama completo, podemos afirmar com segurança que as causas por trás desses conflitos são o modo de vida indígena e a mentalidade de consumo, muitas vezes inconciliáveis.

Por um lado, o modo de vida indígena indica uma cosmogonia centrada no tempo da natureza e nas estações do ano. Aranibar (2009, p. 91, tradução minha), confirma que "o problema surge quando os projetos promovem atividades incompatíveis com a satisfação das necessidades da vida cotidiana, eles podem preferir ir caçar ou cultivar a fazenda em vez de trabalhar oito horas na produção de artesanato ou outra atividade comercial " e explica que a rotina de trabalho industrial, centrada no relógio e no excedente da produção não se adequa àquela "racionalidade organizativa". Para ele (ibidem, p. 91, tradução minha), "A transformação dos povos indígenas em trabalhadores com uma outra rotina é tão difícil e conflituosa quanto qualquer transformação cultural ".

Mesmo a ideia do governo de instituir o turismo boliviano de forma indígena e comunitária não solucionou os conflitos desta vertente, principalmente porque as metas estabelecidas no planejamento não foram concluídas. Esse fato impede uma maior integração das comunidades que não estão diretamente ligadas ao turismo com os viajantes, mas também a própria cultura do povo andino. 
Algumas ações infelizes e até mesmo criminosas de alguns turistas contribuíram com essa desconfiança, tornando parte da população de Uyuni cética quanto a idoneidade dos estrangeiros que, por sua vez, sentem a hostilidade do povo boliviano para com eles. Apesar de não ser um problema generalizado, é estrutural no que tange o tratamento dos anfitriões para com os turistas, mesmo aqueles diretamente ligados à indústria turística. Tal hostilidade não afasta os viajantes de Uyuni, cujos números oficiais de turismo receptivo só crescem. No entanto, a imagem que a cidade e as pessoas deixam nos estrangeiros tende a ser negativa.

Os turistas geralmente ficam apenas um dia em Uyuni e logo seguem viagem com as agências que os levarão às atrações mais importantes do Altiplano Andino. Por esse motivo, o contato com a população local é escasso e pontual. Sendo a natureza a protagonista na viagem e como a cultura local é pouco explorada na região, mesmo com estes conflitos, o turismo cresce e Uyuni se tornou a capital do turismo na Bolívia. Como consequência, os habitantes das cidades da região têm que aguentar muitas vezes a falta de educação de turistas mal orientados, sofrendo com este comportamento.

No geral, pouco se vê daquele que seria o mau comportamento relacionado ao turismo de massas, cuja mentalidade de cliente faz crer que todos trabalham em prol de suas férias e, por sustentar parte considerável daquela população, devem ser gratos por sua presença. Na verdade, os turistas em geral estão mais preocupados com o meio ambiente e com sua experiência durante o tour, desfrutando de um encontro único com a natureza.

\section{Referências Bibliográficas}

ACURISMO. Más de 300 mil turistas visitaron Uyuni el 2016, Uyuniweb. Disponível em <http://uyuniweb.com/especiales/pagina.php?sip=67>. Acessado em 29.04.2018.

ANDERSEN, Lykke E.; VALDEZ, Laura. Turismo en el Salar de Uyuni: Restricciones y Potencialidades. Instituto de Estudios Avanzados en Desarrollo - Serie de Documentos de Trabajo sobre Desarrollo. No. 18/2009, 2010.

APPADURAI, J. Dimensões culturais da globalização. A modernidade sem peias. Editorial Torema Ltda: Lisboa, Portugal, 1996.

ARANIBAR, Ricardo Cox. Turismo indígena y comunitario en Bolivia - Un instrumento para el desarrollo socio-económico e intercultural. La Paz: Plural editores, 2009.

BARRETO, M. Cultura e Turismo - discussões contemporâneas. Campinas, SP: Papirus Editora, 2007. 
COSER, L. A. The functions of social conflict. London, England: Routledge \& Kegan Paul, 1956.

FERNÁNDEZ, Damir Galaz-Mandakovic. Uyuni, capital turística de Bolivia Aproximaciones antropológicas a un fenómeno visual posmoderno desbordante. Teoría y Praxis 16 (147-173), 2014.

GUIMARÃES, V. M. A Sociologia e os Estudos do Turismo: algumas divagações. Trabalho apresentado no GT "Abordagem Histórico-Crítica do Turismo" do V Seminário de Pesquisa em Turismo do Mercosul - Caxias do Sul, 27 e 28 de junho de 2008.

HANNAM, K., e ATELJEVIC, I. Backpacker Tourism: Concepts and Profiles. Toronto: Channel View Publications, 2008.

JAMAL, T. e ROBINSON, M. (orgs.). The Sage Handbook of Tourism Studies, Los Angeles e Londres, Sage, 2009.

JÚNIOR, José O. Alcântara. Georg Simmel e o Conflito Social. Caderno Pós Ciências Sociais - São Luís, v. 2, n. 3, jan./jun. 2005.

KRIPPENDORF, J. Sociologia do Turismo: para uma nova compreensão do lazer e das viagens. Rio de Janeiro: Civilização Brasileira, 1989.

MÓNICO, Lisete S.; ALFERES, Valentim R.; CASTRO, Paulo A. e PARREIRA, Pedro M. A Observação Participante enquanto metodologia de investigação qualitativa. Atas CIAIQ 2017, pp. 724-733.

ROBINSON, M.; BONIFACE, P. Tourism and Cultural Conflicts. Wallingford: CABI Publishing, 1999. Santana, A. Antropologia do Turismo - antologias, encontros e relações. Sao Paulo: Aleph, 2009.

SANTANA, Augustín. Antropologia do Turismo - Analogias, encontros e relações. São Paulo: Aleph, 2009.

SIMMEL, G. Conflict and the web of group affiliations. New York: The Free Press, 1964a.

O conflito como sociação. (Tradução de Mauro Guilherme Pinheiro Koury). RBSE Revista Brasileira de Sociologia da Emoção, v. 10, n. 30, pp. 568-573. ISSN 1676-8965, 1964b. http://www.cchla.ufpb.br/rbse/Index.html

Soziologie - Untersuchung über die Formen der Vergesellschaftung. VillingenSchwenningen: Nexx Verlag, 2015.

UNESCO Bangkok. IMPACT: The Effects of Tourism on Culture and the Environment in Asia and the Pacific:Tourism and Heritage Site Management in Luang Prabang, Lao PDR, 2004. 
UNWTO, World Tourism Organization. Why Tourism? Tourism - an Economic and Social Phenomenon. Acesso dia 6 de outubro de 2013. Disponível em http://www2.unwto.org/en/content/why-tourism.

WAIZBORT, Leopoldo. Simmel no Brasil. DADOS - Revista de Ciências Sociais, Rio de Janeiro, vol. 50, $\mathrm{n}^{\circ} 1,2007$, pp. 11 a 48.

WORLD BANK REPORT, 2012. International Tourism; number of arrivals in Bolivia. In Trading Economics. Acesso dia 10 de outubro de 2013. Disponível em http://www.tradingeconomics.com/bolivia/international-tourism-number-of-arrivals-wbdata.html

YANG, Jingjing, RYAN, Chris and ZHANG, Lingyun, 2012. Social conflict in communities impacted by tourism. Tourism Management number 35 - pgs 82-93.

Recebido em: Maio de 2018 Aprovado em: Julho de 2018 